\title{
Pemetrexed clinical studies in performance status 2 patients with non-small cell lung cancer (Review)
}

\author{
RALPH ZINNER $^{1 *}$, CARLA VISSEREN GRUL $^{2}$, DAVID R. SPIGEL $^{3}$ and COLEMAN OBASAJU ${ }^{4}$ \\ ${ }^{1}$ Departments of Investigational Cancer Therapeutics, and Thoracic/Head and Neck Medical Oncology, \\ Division of Cancer Medicine, The University of Texas MD Anderson Cancer Center, Houston, TX 77030, USA; \\ ${ }^{2}$ EU Lead, Late Phase Development, Lilly Oncology, Lilly Nederland B.V., 3991 RA Houten, The Netherlands; \\ ${ }^{3}$ Sarah Cannon Research Institute, Nashville, TN 37203; ${ }^{4}$ Eli Lilly and Company, Indianapolis, IN 46285, USA
}

Received July 15, 2015; Accepted September 4, 2015

DOI: $10.3892 /$ ijo.2015.3219

\begin{abstract}
Because poor performance status (PS) is an independent prognostic factor in non-small cell lung cancer (NSCLC), PS scores are widely used by oncologists to make treatment decisions. Advanced NSCLC patients with an Eastern Cooperative Oncology Group PS of 2 have poor prognoses and are frequently excluded from clinical trials. This article reviews the efficacy and safety of pemetrexed in this patient group. We identified English-language literature (through March 2015) involving completed and ongoing studies through searches of PubMed, meeting abstracts, ClinicalTrials.gov and the European Clinical Trials Register; search terms included 'pemetrexed,' 'NSCLC' and 'PS2'. Only studies reporting $\geq 1$ subset analysis of PS2 patients receiving pemetrexed were chosen. Our search identified a total of ten pemetrexed studies in PS2 patients. Eight studies included only chemonaive patients, one study included both chemonaive patients and patients with one prior chemotherapy regimen and one study included only patients with one prior regimen. In subset analyses in these studies, PS2 patients had worse outcomes than PS0-1 patients regardless of treatment. In a phase 3 study, chemonaive advanced NSCLC patients with PS2 receiving pemetrexed-carboplatin versus pemetrexed experienced improved overall survival [hazard ratio $(\mathrm{HR})=0.62 ; \mathrm{P}=0.001$ ], progression-free survival $(\mathrm{HR}=0.46 ; \mathrm{P}<0.001)$ and response $(\mathrm{P}=0.032)$. This review confirms the poorer outcomes in PS2 vs. PSO-1 patients. Although it is not an approved combination therapy, in clinical studies, PS2 patients treated with pemetrexed plus
\end{abstract}

Correspondence to: Dr Ralph Zinner, Director of the Thoracic/ Aerodigestive Program at Sidney Kimmel Medical College at Thomas Jefferson University, 925 Chestnut Street, Suite 320A, Philadelphia, PA 19107, USA [*current affiliation]

E-mail: ralphgzinner@gmail.com

Abbreviations: PS2, performance status 2; NSCLC, non-small cell lung cancer

Key words: non-small cell lung cancer, pemetrexed, ECOG PS, clinical trials, LY231514 carboplatin as first-line therapy had improved response rates and survival. Additional research on PS2 patients is needed.

\section{Contents \\ 1. Introduction \\ 2. Methods \\ 3. Results \\ 4. Discussion \\ 5. Conclusion}

\section{Introduction}

Globally, lung cancer is the most commonly diagnosed cancer and leading cause of cancer-related death in males, and the fourth most commonly diagnosed cancer and second most common cause of cancer-related death in females (1). In a meta-analysis published in 1995, cisplatin-based chemotherapy showed a small but statistically significant survival advantage compared with best supportive care (BSC) for treatment of non-small cell lung cancer (NSCLC) (2). The current standard of care for advanced/metastatic NSCLC evolved to platinum-based doublet therapy (or triplet therapy when bevacizumab is included) as first-line therapy of medically fit patients with advanced NSCLC and a performance status (PS) of 0-1 (3-5). More recently, patients with epidermal growth factor receptor mutations are recommended to have first-line erlotinib, gefitinib or afatinib, and patients with anaplastic lymphoma kinase translocations should be treated with crizotinib as first-line therapy $(4,5)$.

Clinicians use PS to make clinical decisions regarding the use of chemotherapy and to make judgments regarding medical fitness for chemotherapy. PS scales are used in an attempt to quantify the well-being and daily life activities of patients with cancer. Additionally, PS is used to determine whether chemotherapy dose adjustments are needed. In clinical trials, PS is used as an enrollment criterion.

The most widely used scales for measuring PS are the Karnofsky Performance Status (KPS) score and the Eastern Cooperative Oncology Group (ECOG) scale (6,7). The KPS 
scale, published in 1949, is expressed as percentages along a continuum with $0 \%$ denoting death and $100 \%$ denoting normal, no complaints, no evidence of disease (7). This scale was developed to enable physicians to evaluate a patient's ability to survive and tolerate chemotherapy. The ECOG scale uses a five-point system, with 0 being asymptomatic and 5 denoting death (6). Conversions between the KPS and ECOG PS scales were validated in lung cancer patients, in which ECOG PS scores of 0-1, 2 and 3-4 are approximately equivalent to KPS scores of $80-100,60-70$ and $10-50 \%$, respectively (8).

PS scales are used by clinicians to guide treatment decisions (9). Patients with an ECOG PS score of 2 are 'ambulatory and capable of all self-care but unable to carry out any work activities; up and about $>50 \%$ of waking hours' (6). The percentage of lung cancer patients with a PS of 2 is estimated to be $20-40 \%$ (8-11). Poor PS is an independent prognostic factor in NSCLC (12-16). Consequently, patients with a PS of 2 are frequently excluded from clinical trials because of historically poorer outcomes and more toxicity compared with patients with a PS of 0-1 (17).

Patients with a PS of 2 are a heterogeneous group (17). PS is affected by both cancer-related symptoms and comorbidities that are unrelated to cancer (9). In a recent review of the literature (18), chemotherapy use and outcomes among patients with cancer (including lung cancer) with comorbidities were generally inferior to patients without comorbidities; however, there was insufficient evidence to conclusively determine the relationship between decreased chemotherapy use and inferior survival. These types of observations and clinical experience may prompt clinicians to treat patients with lung cancer who have a PS of 2 due to lung cancer symptoms more aggressively than patients with lung cancer who have a PS of 2 due to comorbidities.

In first-line treatment of PS2 patients with advanced NSCLC, the decision to use single-agent versus combination therapy is clinically challenging. Until recently, single agents have been the preferred treatment for these patients, but randomized clinical trials have shown that PS2 patients with advanced chemonaive NSCLC can benefit from combination therapy (relative to monotherapy) without excessive toxicity (19-24). Emerging data have prompted the revision of treatment guidelines (Table I) $(3,4)$.

Pemetrexed (Alimta ${ }^{\circledR}$; LY231514), a third-generation multitargeted antifolate (25), is currently approved in the United States (US) and European Union for use in locally advanced or metastatic non-squamous NSCLC in initial first-line treatment in combination with cisplatin, as a single agent in maintenance treatment for patients whose disease has not progressed after 4 cycles of platinum-based first-line chemotherapy, and as second-line treatment after prior therapy (26-32); pemetrexed is also approved for use in combination with cisplatin for unresectable malignant pleural mesothelioma (33). The pemetrexed first-line (31) and maintenance $(27,29,30)$ NSCLC registration trials enrolled patients with a PS of $0-1$, whereas the second-line registration trial enrolled patients with a PS of 0-2 (28). Herein, we present a review of the literature on studies involving the use of pemetrexed in patients with advanced NSCLC and a PS of 2. We also discuss the efficacy and safety of pemetrexed in this patient population.

\section{Methods}

English-language literature involving completed studies was identified through searches of PubMed (database inception through March 2015), proceedings of the American Society of Clinical Oncology (ASCO) (database inception through March 2015) and European Society of Medical Oncology (ESMO) meeting abstracts (from 2011 through March 2015). Ongoing clinical trials were identified by using ClinicalTrials.gov (34) and the European Clinical Trials Register (35); only studies that specifically targeted patients with a PS of 2 were included. Search terms included combinations of 'pemetrexed,' 'NSCLC,' 'performance status,' 'performance status 2,' 'PS2' and 'poor performance status'. References within identified articles were also reviewed. Only studies that reported at least one subset analysis for PS2 patients receiving pemetrexed or reported on PS2 patients receiving pemetrexed exclusively were chosen for this review.

\section{Results}

Our search identified a total of ten pemetrexed studies in PS2 patients (Tables II-IV) (19,28,36-43). Eight studies included only chemonaive patients (19,36-38,40-43), one study included both chemonaive patients and patients with one prior chemotherapy regimen (39) and one study included only patients with one prior regimen (28). Only one randomized trial was dedicated to the use of pemetrexed exclusively in chemonaive patients with an ECOG PS of 2 (19). In some studies, data pertaining specifically to PS2 patients were limited. All but two trials $(36,43)$ included folic acid and vitamin B12 supplementation and dexamethasone per the pemetrexed label (26). Six trials included patients with squamous histology $(19,28,36,37,40,41)$, as these trials predated the revision of the pemetrexed indication excluding squamous patients (26).

\section{Completed pemetrexed clinical trials including PS2 patients}

First-line pemetrexed single-agent therapy. Clarke et al performed an international, single-arm, phase 2 trial in patients with advanced NSCLC (36). Eligibility requirements included being chemonaive, having stage IIIA/B or IV NSCLC (of both squamous and non-squamous histology) and having an ECOG PS of 0-2 (Table II). Patients received $600 \mathrm{mg} / \mathrm{m}^{2}$ pemetrexed every 3 weeks (q3w) for a maximum of 12 cycles (without vitamin supplementation). The aims were to investigate the activity and toxicity of pemetrexed in this patient population.

Fifty-nine patients were enrolled (36). The median age was 59 years (range, 39-74 years), 32\% (19/59) of patients had a PS of $2,34 \%$ were female, $66 \%$ had stage IV disease, and $17 \%$ of patients had squamous histology. The response rate in patients with a PS of 2 was $5 \%$, whereas it was $18 \%$ in patients with a PS of $0-1$ and $16 \%$ overall. The effects of PS on dose delivery and tolerability were not reported. On the basis of response rate, the authors concluded that pemetrexed treatment should be restricted to patients with a PS of $0-1$. It should be noted that the pemetrexed dose used in this trial exceeded the now registered dose of $500 \mathrm{mg} / \mathrm{m}^{2}$, and this trial predated the use of vitamin supplementation and allowed patients with squamous histology. As such, toxicities in this trial are more pronounced than in later studies. 
Table I. Treatment guidelines for PS2 or elderly patients with advanced non-small cell lung cancer.

\begin{tabular}{|c|c|c|c|}
\hline Organization & Date & Guidelines & Source (ref.) \\
\hline ASCO & 2011 & $\begin{array}{l}\text { 'Evidence supports use of chemotherapy in patients with } \\
\text { stage IV NSCLC with ECOG/Zubrod PS of } 0,1 \text {, } \\
\text { possibly } 2 \text {. Available data support use of single-agent } \\
\text { chemotherapy in patients with a PS of } 2 \text {; data are } \\
\text { insufficient to make recommendation for or against using } \\
\text { combination of two cytotoxic drugs in patients with a } \\
\text { PS of } 2 \text {. Evidence does not support selection of specific } \\
\text { first-line chemotherapy drug or combination } \\
\text { based on age alone.' }\end{array}$ & $\begin{array}{l}\text { Azzoli CG, Temin S, Aliff T, Baker S, Brahmer J, } \\
\text { Johnson DH, Laskin JL, Masters G, Milton D, } \\
\text { Nordquist L, et al: } 2011 \text { focused update of } 2009 \\
\text { American Society of Clinical Oncology Clinical } \\
\text { Practice guideline update on chemotherapy for } \\
\text { stage IV non-small-cell lung cancer. J Clin } \\
\text { Oncol 29: 3825-3831, 2011. (3) }\end{array}$ \\
\hline ESMO & 2014 & $\begin{array}{l}\text { 'Chemotherapy prolongs survival and possibly improves } \\
\text { QoL in NSCLC patients with PS 2, when compared with } \\
\text { BSC (I, B). Single-agent chemotherapy with gemcitabine, } \\
\text { vinorelbine, and taxanes represents an option (I, B). } \\
\text { Carboplatin-based combination chemotherapy should be } \\
\text { considered in eligible PS } 2 \text { patients (II, A). A survival } \\
\text { advantage has been seen for carboplatin-based } \\
\text { chemotherapy in eligible patients aged 70-89 years with } \\
\text { PS 0-2 with adequate organ function (I, B). For the other } \\
\text { clinically unselected patients with advanced NSCLC, } \\
\text { single-agent chemotherapy remains the standard of care } \\
\text { for first-line therapy patients (I, B).' }\end{array}$ & $\begin{array}{l}\text { Reck M, Popat S, Reinmuth N, De Ruysscher D, } \\
\text { Kerr KM and Peters S; ESMO Guidelines } \\
\text { Working Group: Metastatic non-small-cell lung } \\
\text { cancer (NSCLC): ESMO Clinical Practice } \\
\text { Guidelines for diagnosis, treatment and } \\
\text { follow-up. Ann Oncol } 25 \text { (suppl 3): } \\
\text { iii27-iii39, 2014. (4) }\end{array}$ \\
\hline
\end{tabular}

ASCO, American Society of Clinical Oncology; BSC, best supportive care; ESMO, European Society for Medical Oncology; NSCLC, non-small cell lung cancer; PS, performance status; QoL, quality of life.

Gridelli et al performed an open-label, randomized, phase 2 trial comparing single-agent pemetrexed $\left(500 \mathrm{mg} / \mathrm{m}^{2} \mathrm{q} 3 \mathrm{w}\right.$ for 8 cycles) to sequential pemetrexed-gemcitabine (pemetrexed $500 \mathrm{mg} / \mathrm{m}^{2} \mathrm{q} 3 \mathrm{w}$ for cycles 1 and 2 followed by $1,200 \mathrm{mg} / \mathrm{m}^{2}$ gemcitabine on days 1 and $8 \mathrm{q} 3 \mathrm{w}$ for cycles 3 and 4 repeated once for a total of 8 cycles) (Table II) (37). Eligible patients had stage IIIB or IV NSCLC (of both squamous and non-squamous histology), were chemonaive, had an ECOG PS of 0-2, and were at least 70 years old or less than 70 years old, but ineligible for platinum-based chemotherapy. The primary endpoint was time-to-progressive disease (TtPD).

Of the 92 randomized patients, 87 were treated (44 pemetrexed and 43 pemetrexed-gemcitabine) (37). The median age was 73 years (range, 58-82 years) for patients receiving pemetrexed and 73 years (range, 61-83 years) for those receiving pemetrexed-gemcitabine; $14 / 44$ patients (32\%) receiving pemetrexed and $17 / 43$ patients $(40 \%)$ receiving pemetrexed-gemcitabine had a PS of 2. Among patients receiving pemetrexed and pemetrexed-gemcitabine, 21 and $33 \%$ were female, 82 and $81 \%$ had stage IV disease, and 25 and $35 \%$ had squamous histology, respectively. Because many patients died in the absence of documented progression, there was a high rate of censoring for TtPD. Consequently, progression-free survival (PFS) was added retrospectively as this endpoint was expected to have less censoring than TtPD. The median PFS was 3.3 months for each treatment arm, and the median overall survival (OS) was 4.7 months for pemetrexed and 5.4 months for pemetrexed-gemcitabine. In an exploratory analysis of patients with a PS of 2 who received pemetrexed and pemetrexed-gemcitabine, the median PFS was 1.3 and 1.9 months, respectively; in patients with a PS of $0-1$, the median PFS was 4.4 months for pemetrexed and 3.7 months for pemetrexed-gemcitabine. The median OS was 1.8 and 3.9 months in patients with a PS of 2, and was 5.2 and 7.6 months in patients with a PS of 0-1 for pemetrexed and pemetrexed-gemcitabine, respectively. The between-arm differences were not significant for the subgroups. The effects of PS on dose delivery and tolerability were not reported. The authors noted that the study confirmed that a PS of 2 predicted poor outcomes and that studies dedicated to patients with a PS of 2 were needed. The authors concluded that either treatment was appropriate for further study in more homogeneous patient populations such as elderly patients who are unsuitable for treatment with platinumbased combination chemotherapy (i.e., patients with a PS of 2). Pemetrexed is not approved as a single-agent first-line therapy or in combination with gemcitabine. There was no blinding in the study, thus investigator bias may have been introduced, and there was a high level of censoring for TtPD (37).

Second-line pemetrexed single-agent therapy. In a large, phase 3 , registration trial, Hanna et al randomized previously-treated patients with advanced NSCLC to receive pemetrexed $\left(500 \mathrm{mg} / \mathrm{m}^{2} \mathrm{q} 3 \mathrm{w}\right)$ or docetaxel (75 mg/m² q3w) (Table II) (28). Eligibility criteria included having stage III or IV NSCLC (of both squamous and non-squamous histology), having received 1 prior regimen for advanced disease and having an ECOG PS of 0-2. This was a noninferiority trial with a primary endpoint of OS. At the time of this study, single-agent docetaxel had already been approved as second-line therapy $(44,45)$. 
Table II. Published completed studies of single-agent pemetrexed in PS2 patients.

Authors, year (ref.),

Treatment type,

Endpoint
Study design/ phase
Study population
Treatment $^{\mathrm{a}}$

ORR

mPFS and mOS

Grades 3 or 4 AEs occurring in patients in either arm and deaths ${ }^{\mathrm{b}}$

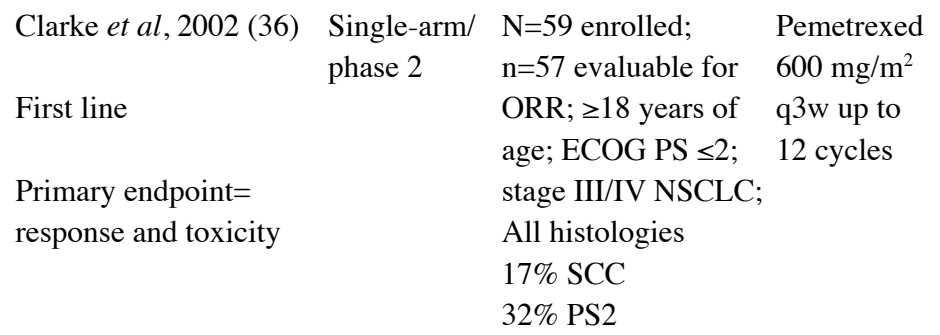

$\begin{array}{ll}\text { All: } 15.8 \% & \text { mPFS } \\ \text { (95\% CI, 7-28) } & \text { All: NR } \\ \text { PS0-1: } 18 \% & \text { PS0-1: NR } \\ \text { (95\% CI, NR) } & \text { PS2: NR } \\ \text { PS2: 5\% } & \\ \text { (95\% CI, NR) } & \text { mOS } \\ & \text { All: } 7.2 \text { months } \\ & \text { PS0-1: NR } \\ & \text { PS2: NR }\end{array}$
All (\% Grade 3/\% Grade 4):
Lymphopenia 44/32
Neutropenia 27/15
Leukopenia 27/7
Anemia 7/3
Thrombocytopenia $0 / 5$
Febrile neutropenia 3/0
ALT/AST 20/0*
Cutaneous 19/12
Nausea 14/0
Vomiting 5/3
Fatigue 5/0
Mucositis 5/0
Death: not reported
*Asymptomatic

\begin{tabular}{|c|c|c|c|}
\hline Gridelli et al, 2007 (37) & $\begin{array}{l}\text { Open-label } \\
\text { randomized/ } \\
\text { phase } 2\end{array}$ & $\begin{array}{l}N=92 \text { enrolled; } \\
\geq 70 \text { or }<70 \text { years of } \\
\text { age if ineligible for } \\
\text { platinum-based }\end{array}$ & $\begin{array}{l}\text { Pemetrexed } \\
500 \mathrm{mg} / \mathrm{m}^{2} \\
\mathrm{q} 3 \mathrm{w} \text { up to } \\
8 \text { cycles }\end{array}$ \\
\hline $\begin{array}{l}\text { Primary endpoint= } \\
\text { TtPD }\end{array}$ & & $\begin{array}{l}\text { chemotherapy; } \\
\text { ECOG PS of 0-2; } \\
\text { stage IIIB or IV } \\
\text { NSCLC; } \\
\text { All histologies } \\
\text { Pem (n=44): } \\
25.0 \% \text { SCC } \\
31.8 \% \text { PS } 2 \\
\text { Sequential } \\
\text { Pem/Gem } \\
\text { (n=43): } \\
34.9 \% \text { SCC } \\
39.5 \% \text { PS2 }\end{array}$ & $\begin{array}{l}\quad \text { vs. } \\
\text { Pemetrexed } \\
500 \mathrm{mg} / \mathrm{m}^{2} \\
\text { on day } 1 \text { for } \\
\text { cycles } 1 \text { and } 2 \\
\text { followed by } \\
\text { gemcitabine } \\
1,200 \mathrm{mg} / \mathrm{m}^{2} \\
\text { on days } 1 \\
\text { and } 8 \mathrm{q} 3 \mathrm{w} \text { for } \\
\text { cycles } 3 \text { and } 4 \\
\text { repeated once } \\
\text { for a total of } \\
8 \text { cycles }\end{array}$ \\
\hline
\end{tabular}

All Pem:
$4.5 \%(95 \%$
CI, 0.6-15.5)
Sequential
Pem/Gem:
$11.6 \%(95 \%$
CI, 3.9-25.1)

Pem: mOS

All: 4.7 months (95\% CI, 3.2-6.8)

(\% Grade 3/\% Grade 4) All Pem:

PS0-1: 5.2 months* Thrombocytopenia 2.3/2.3

PS2: 1.8 months ${ }^{*} \quad$ Febrile neutropenia $4.5 / 0$

Pulmonary 4.5/0

mPFS

Mucositis 4.5/0

All: 3.3 months $\quad$ All sequential Pem/Gem:

(95\% CI, 2.0-4.4) Thrombocytopenia 7.0/0

PS0-1: 4.4 months* Febrile neutropenia 4.7/0

PS2 $=1.3$ months ${ }^{*} \quad$ Anemia 4.7/0

Neutropenia 2.3/0

Sequential Rash $4.7 / 0$

Pem/Gem:

mOS

Deaths (both arms):

All: 5.4 months $\quad 12$, none attributed to (95\% CI, 3.8-7.6) study drug

PS0-1: 7.6 months*

PS2: 3.9 months ${ }^{*}$

mPFS

All: 3.3 months

(95\% CI, 1.7-4.1)

PSO-1: 3.7 months*

PS2: 1.9 months ${ }^{*}$

Within PS0-1 and

PS2 subgroups,

between arm

differences not

significant

${ }^{*} 95 \%$ CI, NR
Hanna et al, 2004 (28) Randomized/ N=571 phase 3

Second line

Noninferiority

Primary endpoint=OS randomized;

ECOG PS of 0-2; stage III or IV NSCLC; 1 prior chemotherapy for advanced disease;
Pemetrexed

$500 \mathrm{mg} / \mathrm{m}^{2}$

q3w

vs.

Docetaxel

$75 \mathrm{mg} / \mathrm{m}^{2}$

$\mathrm{q} 3 \mathrm{w}$

\section{All Pem: 9.1\% Pem:}

mOS

All Doc: $8.8 \%$ All: 8.3 month PS0-1: NR

PS2: NR

PS0-1: 9.4 months PS2: 3.6 months

\section{All Pem (\%):}

Neutropenia 5.3

Anemia 4.2

Febrile neutropenia 1.9

Thrombocytopenia 1.9

Neutropenia w/ infection 0

Fatigue 5.3 
Table II. Continued.

\begin{tabular}{|c|c|c|c|c|c|c|}
\hline $\begin{array}{l}\text { Authors, year (ref.), } \\
\text { Treatment type, } \\
\text { Endpoint }\end{array}$ & $\begin{array}{c}\text { Study } \\
\text { design/phase }\end{array}$ & Study population & Treatment $^{\mathrm{a}}$ & ORR & $\mathrm{mPFS}$ and $\mathrm{mOS}$ & $\begin{array}{c}\text { Grades } 3 \text { or } 4 \text { AEs occurring } \\
\text { in patients in either arm } \\
\text { and deaths }{ }^{\mathrm{b}}\end{array}$ \\
\hline & & $\begin{array}{l}\text { All histologies } \\
\begin{array}{l}\text { Pem (n=283): } \\
n=265 \text { treated } \\
27.6 \% \text { SCC } \\
11.4 \% \text { PS2 } \\
\text { Doc ( } \mathbf{n = 2 8 8 ) :} \\
n=276 \text { treated } \\
32.3 \% \text { SCC } \\
12.4 \% \text { PS2 }\end{array}\end{array}$ & $\begin{array}{l}\text { Both arms: } \\
\text { Cycles were } \\
\text { repeated until } \\
\text { the disease } \\
\text { progressed, } \\
\text { the patient } \\
\text { experienced } \\
\text { unacceptable } \\
\text { toxicity, or the } \\
\text { patient or the } \\
\text { investigator } \\
\text { requested } \\
\text { therapy } \\
\text { discontinuation }\end{array}$ & & $\begin{array}{l}\text { mPFS } \\
\text { All: } 2.9 \text { months } \\
\text { PS0-1: NR } \\
\text { PS2: NR } \\
\text { Doc: } \\
\text { mOS } \\
\text { All: } 7.9 \text { months } \\
\text { PS0-1: } 9.1 \text { months; } \\
\text { P=0.996 } \\
\text { PS 2: } 2.2 \text { months; } \\
\text { P=0.264 } \\
\text { mPFS } \\
\text { All: } 2.9 \text { months } \\
\text { PS0-1: NR } \\
\text { PS2: NR } \\
\text { Pem OS vs. Doc OS } \\
\text { HR=0.99 } \\
\text { (95\% CI, 0.82-1.2) } \\
\text { P=0.226 }\end{array}$ & 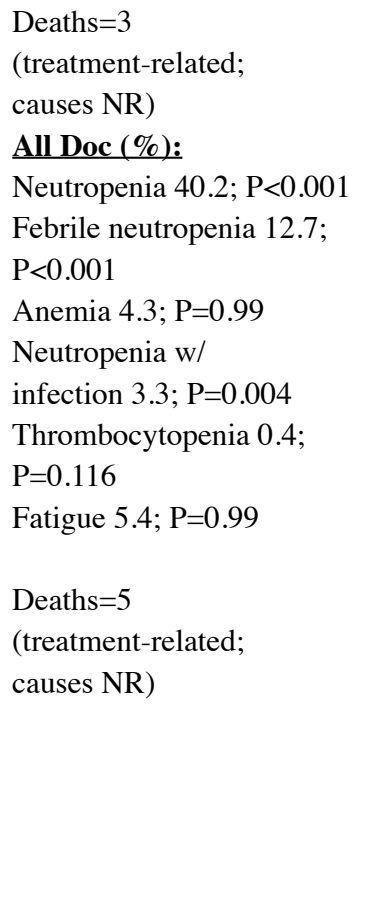 \\
\hline
\end{tabular}

${ }^{a}$ Patients received folic acid and vitamin B12 and dexamethasone $(28,37)$, except patients in the study by Clark et al (36). ${ }^{b}$ Includes all grade 3 or 4 hematologic AEs, deaths, and grade 3 or 4 nonhematologic AEs occurring in $\geq 5 \%$ of patients in either arm. All, overall population; AE, adverse events; ALT, alanine aminotransferase; AST, aspartate transaminase; CI, confidence interval; Doc, docetaxel; ECOG, Eastern Cooperative Oncology Group; Gem, gemcitabine; HR, hazard ratio; m, median; $\mathrm{n}$, number of patients in the specified category; N, population size; NR, not reported; NSCLC, non-small cell lung cancer; ORR, objective response rate; OS, overall survival; Pem, pemetrexed; PFS, progression-free survival; PS, performance status; q3w, every 3 weeks; SCC, squamous cell carcinoma; TtPD, time-to-progressive disease; vs., versus.

Of the 571 randomized patients, 265 received pemetrexed and 276 received docetaxel (28). The median age (pemetrexed/docetaxel) was 59 (range, 22-81 years)/57 years (range, $28-87$ years), $11 / 12 \%$ had a PS of $2,31 / 25 \%$ were female, $75 / 75 \%$ had stage IV disease and $28 / 32 \%$ had squamous histology. The median OS in PS2 patients was (pemetrexed/docetaxel) 3.6/2.2 months, whereas it was 9.4/9.1 months in PS0-1 patients and 8.3/7.9 months overall; the between-arm differences were not significant. Factors significantly associated with increased survival were: $\mathrm{PS}$ of 0 or $1(\mathrm{HR}=0.25,95 \% \mathrm{CI}, 0.19-0.34$; $\mathrm{P}<0.001)$, stage III disease $(\mathrm{HR}=0.77,95 \% \mathrm{CI}, 0.60-0.97$; $\mathrm{P}=0.026)$, and longer time since last chemotherapy $(\mathrm{HR}=0.74$, 95\% CI, 0.60-0.97; $\mathrm{P}=0.004)$. The effects of PS on dose delivery and tolerability were not reported.

An open-label, phase 2, single-arm study is investigating the use of pemetrexed monotherapy (plus vitamin supplementation) in PS2 patients with advanced NSCLC (Table III) (39). The study included both chemonaive patients and patients with one prior chemotherapy who had stage IIIB or IV NSCLC, and a Zubrod PS2 or PS3. This study has been completed, but study data are not available yet.

First-line pemetrexed combination therapy. Blakely et al performed a single-arm phase 2 trial testing the combination of pemetrexed $\left(500 \mathrm{mg} / \mathrm{m}^{2} \mathrm{q} 2 \mathrm{w}\right)$ and gemcitabine $(1,500 \mathrm{mg} /$ $\mathrm{m}^{2} \mathrm{q} 2 \mathrm{w}$ ) for up to 12 cycles (Table IV) (40). Eligibility criteria included age $\geq 65$ years, ECOG PS of $0-2$, and stage IIIB or IV NSCLC (of both squamous and non-squamous histology); patients $<65$ years were eligible if they had a PS of 2 . Patients had to be chemonaive. The primary endpoint was objective response rate (ORR). Forty-five patients with a mean (SD) age of 72 (6.7) years (range, 46.1-88.0 years) were enrolled, $13 / 45$ patients $(29 \%)$ had an ECOG PS of 2, $44 \%$ were female, and $89 \%$ had stage IV disease (40). Only $5 / 13$ patients $(38 \%)$ with a PS of 2 were evaluable for response. Of these, there were no responses, but 1 patient had stable disease lasting longer than 24 weeks. In contrast, $26 / 32$ patients $(81 \%)$ with a PS of $0-1$ were evaluable for response, and among these the ORR [complete response $(\mathrm{CR})+$ partial response $(\mathrm{PR})]$ was $25 \%(\mathrm{CI}, 13.3 \%$ 42.1\%). The difference in response between patients with a PS of 2 and those with a PS of $0-1$ was not significant $(\mathrm{P}=0.083)$; however, this subgroup analysis was unplanned and few patients with a PS of 2 were evaluable. The median PFS was 1.6 months (CI, 1.2-2.0) in patients with a PS of 2, 3.8 months (CI, 2.9-4.8) in patients with a PS of $0-1$, and 3.5 months (CI, 2.3-4.6) overall. The median PFS difference between patients with a PS of 2 and those with a PS of $0-1$ was statistically significant $(\mathrm{P}=0.011)$, although this subgroup analysis was unplanned.

Of the 6 patients who died during the study, all had a PS of 2 at baseline (40). However, none of these deaths were attrib- 
Table III. Unpublished clinical trials of pemetrexed in PS2 patients.

\begin{tabular}{|c|c|c|c|c|c|}
\hline Sponsor/identifier & Status $^{\mathrm{a}}$ & Study design/phase & Study population $^{\mathrm{b}}$ & Treatment & Primary endpoint \\
\hline $\begin{array}{l}\text { Fudan University (China)/ } \\
\text { Clinicaltrials.gov: } \\
\text { NCT01860508 (38) }\end{array}$ & Recruiting & $\begin{array}{l}\text { Open-label } \\
\text { single-arm }\end{array}$ & $\begin{array}{l}\text { Non-squamous } \\
\text { stage IV NSCLC; } \\
\geq 65 \text { years or } \\
\text { PS2; First-line; } \\
\text { Target }=94\end{array}$ & $\begin{array}{l}\text { Pemetrexed/ } \\
\text { carboplatin } \rightarrow \\
\text { Pemetrexed } \\
\text { maintenance } \\
\text { (regimen not } \\
\text { reported) }\end{array}$ & PFS \\
\hline $\begin{array}{l}\text { MD Anderson } \\
\text { Eli Lilly and Company } \\
\text { Clinicaltrials.gov: } \\
\text { NCT00508144 (39) }\end{array}$ & Completed & $\begin{array}{l}\text { Open-label } \\
\text { single-arm/phase } 2\end{array}$ & $\begin{array}{l}\text { Stage IIIB or IV } \\
\text { NSCLC; Zubrod } \\
\text { PS } 2 \text { or PS } 3 ; \leq 1 \text { prior } \\
\text { chemotherapy; second-line } \\
\text { Target }=70\end{array}$ & $\begin{array}{l}\text { Pemetrexed } \\
500 \mathrm{mg} / \mathrm{m}^{2} \mathrm{q} 3 \mathrm{w}, \\
\text { until progression } \\
\text { or unacceptable } \\
\text { toxicity }\end{array}$ & $\begin{array}{l}\text { ORR (PS2) } \\
\text { Descriptive (PS3) }\end{array}$ \\
\hline
\end{tabular}

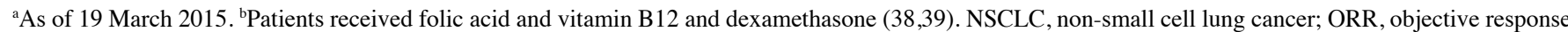
rate; PFS, progression-free survival; PS, performance status; q3w, every 3 weeks.

utable to treatment-related adverse events (AEs) and the AEs experienced by these patients were similar to those of other patients. The probability of experiencing a grade 3 or $4 \mathrm{AE}$ did not differ between these 6 patients and the entire cohort. Overall, the occurrence of grade 3 or 4 AEs was unrelated to PS (and unrelated to disease stage, ethnicity, elderly status, and histological subtype). The authors concluded that patients with a PS of 2 fared poorly in this trial, regardless of age, and that there was high early mortality with poor responses to therapy.

In an open-label phase 3 trial, Grønberg et al randomized patients with advanced NSCLC to pemetrexed $\left(500 \mathrm{mg} / \mathrm{m}^{2}\right.$ on day $1 \mathrm{q} 3 \mathrm{w}$ ) with carboplatin (AUC $=5$ on day $1 \mathrm{q} 3 \mathrm{w}$ ) or gemcitabine $\left(1,000 \mathrm{mg} / \mathrm{m}^{2}\right.$ on days 1 and $\left.8 \mathrm{q} 3 \mathrm{w}\right)$ with carboplatin ( $\mathrm{AUC}=5$ on day $1 \mathrm{q} 3 \mathrm{w}$ ); regimens were repeated for up to 4 cycles (Table IV) (41). Eligibility criteria included being chemonaive, having stage IIIB or IV NSCLC (of both squamous and non-squamous histology), and having a WHO PS of 0-2. The primary endpoint was health-related quality of life (HRQoL), as measured by the European Organisation for Research and Treatment of Cancer Quality of Life Questionnaire Core 30.

Overall, 446 patients were enrolled in this study (41). The median age was 64 (range, 35-90 years) for patients receiving pemetrexed-carboplatin and 66 years (range, 25-84 years) for patients receiving gemcitabine-carboplatin; 47/219 patients $(21.5 \%)$ and $49 / 217$ patients $(22.6 \%)$ had a WHO PS of 2 . A total of 44 and $41 \%$ of the patients receiving pemetrexed-carboplatin and gemcitabine-carboplatin were female, respectively, and 71 and $72 \%$ had stage IV NSCLC, respectively. There were no significant between-arm differences for the primary HRQoL endpoints. Of the enrolled patients, 436 patients (219 receiving pemetrexed-carboplatin; 217 receiving gemcitabine-carboplatin) were eligible for the survival analysis. Among patients who received respective treatments of pemetrexed-carboplatin and gemcitabine-carboplatin, the median OS was 4.3 and 5.1 months for patients with a PS of 2,8.7 and 7.7 months in patients with a PS of $0-1$ and 7.3 and 7.0 months overall. The between-differences were not significant in either PS category. The effects of PS on dose delivery, tolerability, and HRQoL were not reported. The authors noted that OS in the overall/ intent-to-treat (ITT) patient population was shorter than other trials investigating gemcitabine with platinum, but this trial had a relatively high proportion of PS2 patients.

To date, the only completed prospective clinical trial evaluating the use of pemetrexed specifically in PS2 patients was performed by Zukin et al in multiple Brazilian centers and one US center (Table IV) (19). This trial was designed prior to the approval of pemetrexed for first-line therapy $(26,31,32)$ and the knowledge of the interaction between histological subtype and pemetrexed efficacy $(46,47)$. The protocol was later amended to exclude patients with squamous histology. Patients with advanced NSCLC were randomized to receive pemetrexed $\left(500 \mathrm{mg} / \mathrm{m}^{2} \mathrm{q} 3 \mathrm{w}\right)$ or pemetrexed $\left(500 \mathrm{mg} / \mathrm{m}^{2} \mathrm{q} 3 \mathrm{w}\right)$ with carboplatin (AUC $=5 \mathrm{q} 3 \mathrm{w}$ ), both for 4 cycles. Eligibility criteria included having an ECOG PS of 2, stage IIIB/IV NSCLC and no prior chemotherapy. The primary endpoint was OS (19). At the main center in Brazil where $>60 \%$ of the patients were enrolled during this trial, two independent investigators had to agree on the ECOG PS2 assignment before the patient was enrolled (19).

Overall, 217 eligible patients were enrolled, comprising 109 in the pemetrexed arm and 108 in the pemetrexed-carboplatin arm (19). The median age (pemetrexed/pemetrexed-carboplatin) was 65 (range, 40-86 years)/65 years (range, 41-90 years), $41 / 37 \%$ were female, $95 / 94 \%$ had stage IV NSCLC and $11 / 3 \%$ had squamous histology. Comorbidities included (pemetrexed/pemetrexed-carboplatin): hypertension (45.1/44.7\%), chronic obstructive pulmonary disease (17.6/11.7\%) and diabetes mellitus (7.8/12.6\%). Overall, $53.9 \%$ of patients receiving pemetrexed completed the planned treatment, in comparison to $70.9 \%$ of patients receiving pemetrexed-carboplatin $(\mathrm{P}=0.012)$. Reasons for treatment discontinuation included (pemetrexed/pemetrexed-carboplatin): early death (14.7/9.7\%), early progression $(15.7 / 7.8 \%)$, clinical deterioration $(12.7 / 6.8 \%)$ and toxicity $(0 / 1.9 \%)$. The authors commented that, during this study, investigator bias may have been introduced regarding patient selection; patients may not be representative of the average ECOG 2 population. In the ITT patient population, patients receiving combination therapy experienced improved $\mathrm{OS}(\mathrm{HR}=0.62,95 \% \mathrm{CI}, 0.46-0.83$; 


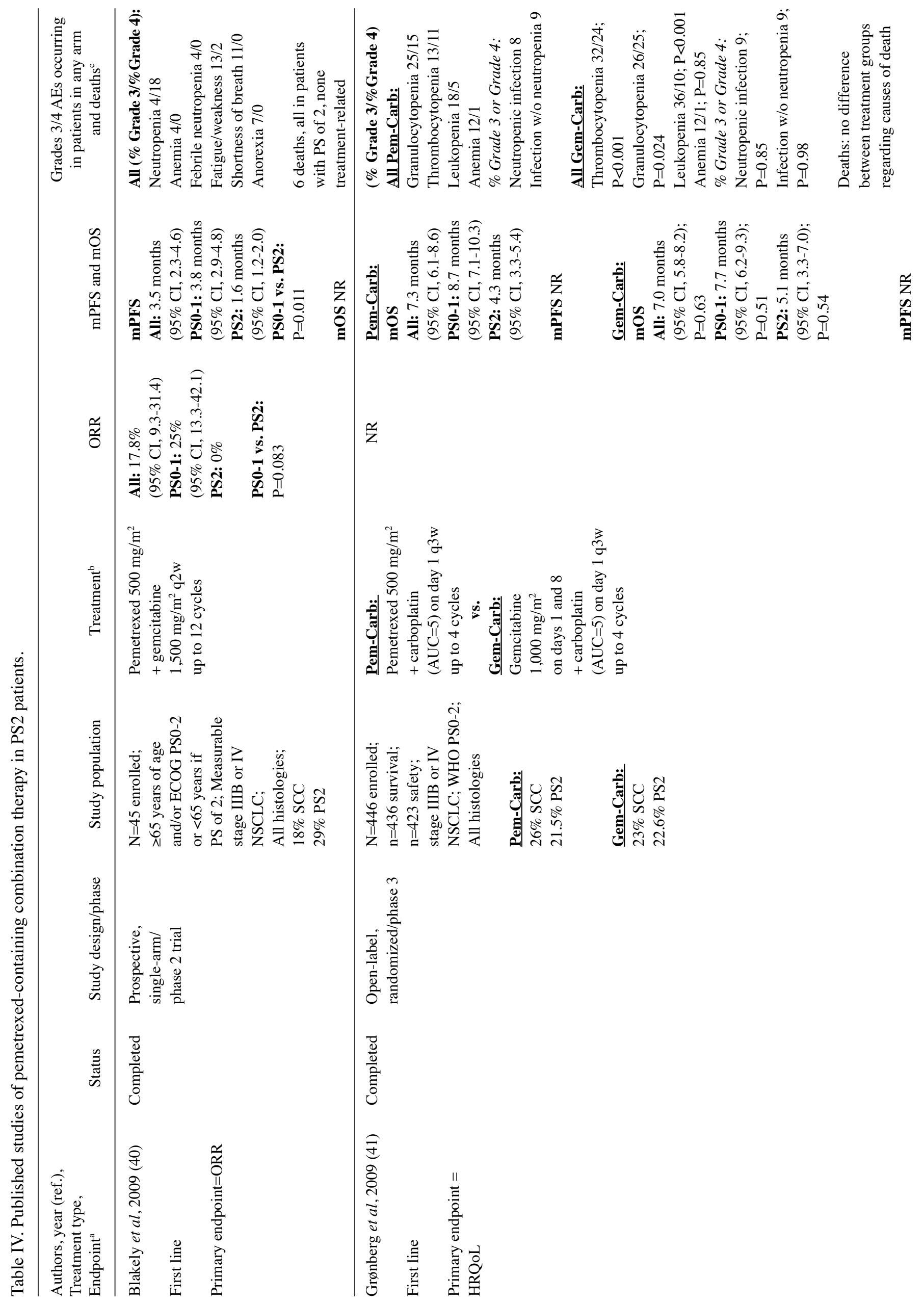




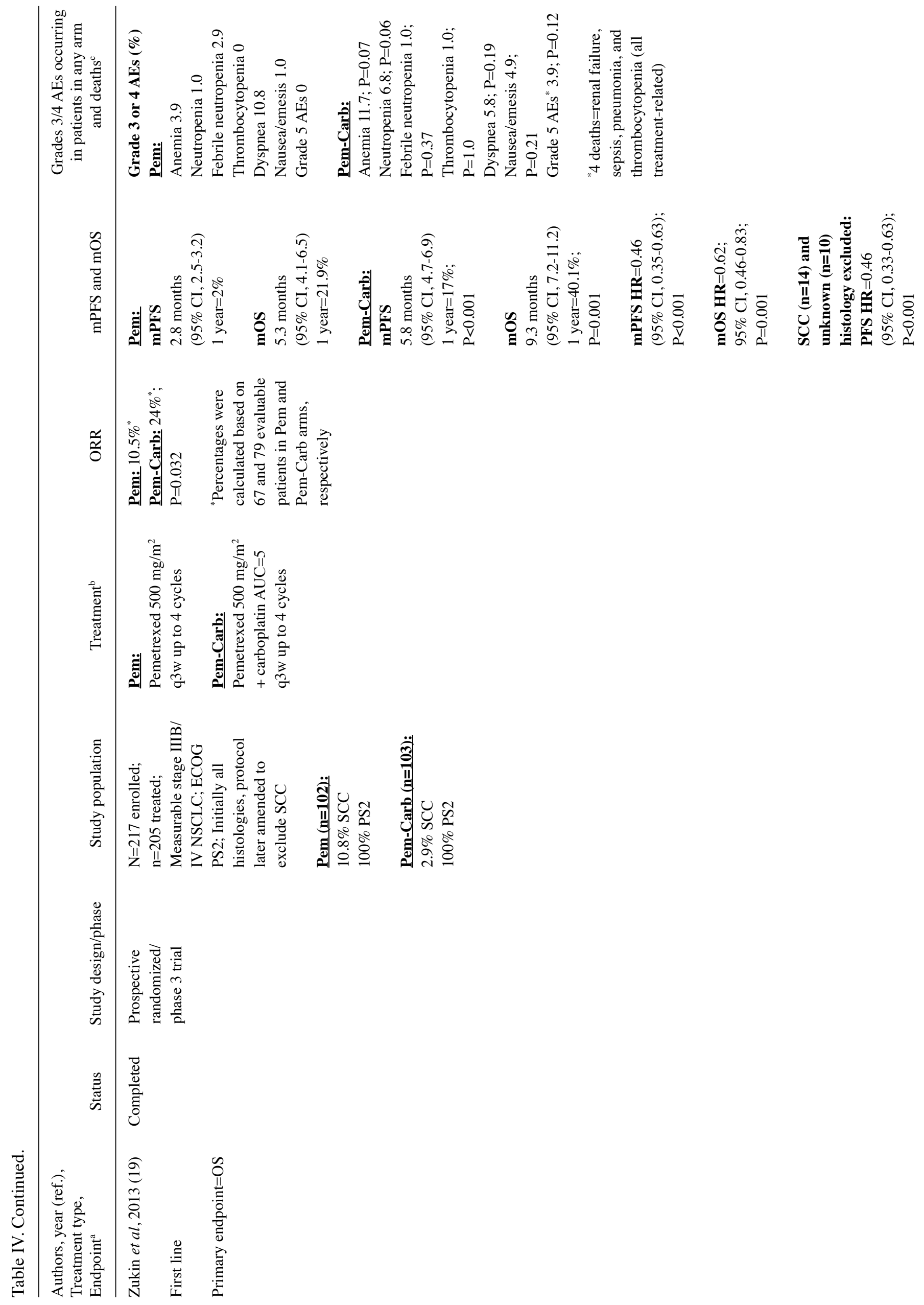




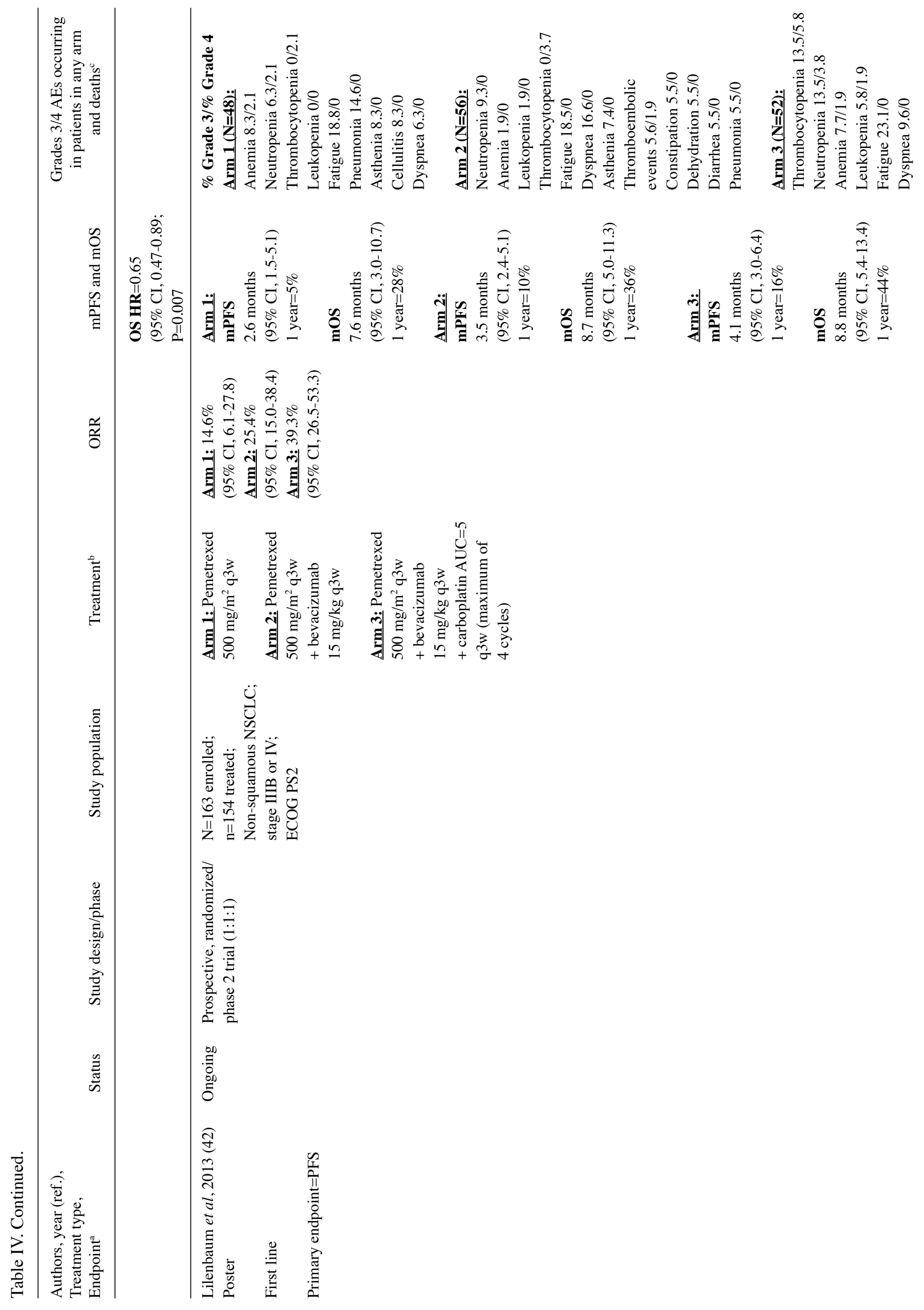




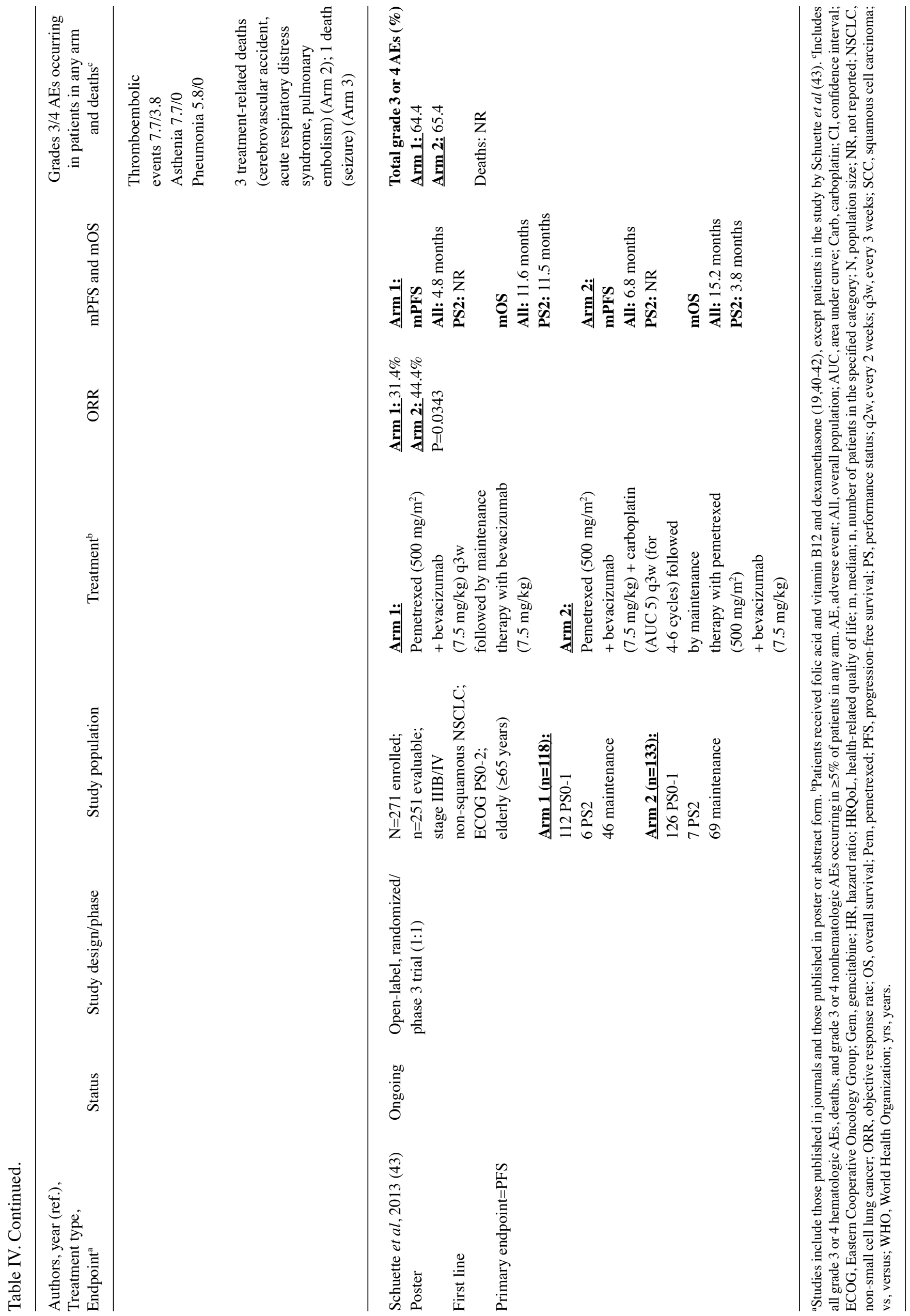


median, 9.3 vs. 5.3 months; $\mathrm{P}=0.001)$, $\mathrm{PFS}$ (HR=0.46, 95\% CI, 0.35-0.63; median 5.8 vs. 2.8 months; $\mathrm{P}<0.001$ ), and ORR ( 24 vs. $10.5 \%$; $\mathrm{P}=0.032$ ) (19). To confirm the results in the pemetrexed-eligible population of non-squamous NSCLC, patients with squamous cell carcinoma $(\mathrm{n}=14)$ and unknown histology $(\mathrm{n}=10)$ were excluded from the data set (19). The HRs for OS (HR=0.65, 95\% CI, 0.47-0.89; $\mathrm{P}=0.007)$ and PFS $(\mathrm{HR}=0.46,95 \% \mathrm{CI}, 0.33-0.63 ; \mathrm{P}<0.001)$ were similar to those of the ITT population.

Grade 3 and 4 AEs for patients receiving pemetrexed vs. those receiving pemetrexed-carboplatin included anemia (3.9 vs. $11.7 \%$ ), neutropenia (1.0 vs. $6.8 \%$ ), thrombocytopenia ( 0 vs. $1.0 \%$ ), febrile neutropenia ( 2.9 vs. $1.0 \%$ ), nausea/emesis (1.0 vs. $4.9 \%)$, diarrhea (2.0 vs. $1.0 \%)$ and dyspnea (10.8 vs. $5.8 \%)$ (19). The authors noted that the apparently increased dyspnea incidence in the pemetrexed arm was most likely a manifestation of the disease rather than treatment toxicity. There were 4 treatment-related deaths $(3.9 \%)$ in the combination arm (vs. $0 \%$ in the single-agent arm) due to renal failure, sepsis, pneumonia and thrombocytopenia. The authors concluded that combination therapy offered improved outcomes relative to single-agent therapy and should be offered to PS2 patients. Pemetrexed in combination with carboplatin is not an approved therapy however. It was noted that the mortality rate was higher than anticipated, although not unexpected, for PS0-1 patients receiving a carboplatin doublet, thus PS2 patients should be closely monitored throughout treatment.

In a German multicenter, open-label, phase 3 trial, patients were randomized $1: 1$ to pemetrexed $\left(500 \mathrm{mg} / \mathrm{m}^{2}\right)$ plus bevacizumab $(7.5 \mathrm{mg} / \mathrm{kg})$ or pemetrexed plus bevacizumab and carboplatin $(\mathrm{AUC}=5) \mathrm{q} 3 \mathrm{w}$ for $4-6$ cycles, followed by maintenance therapy with bevacizumab or pemetrexed-bevacizumab (Table IV) (43). Eligibility criteria included stage IIIB/IV non-squamous NSCLC, age $\geq 65$ years and ECOG PS of 0-2. The primary endpoint was PFS. Of the 271 patients who were enrolled, 251 (pemetrexed-bevacizumab; $n=118$; pemetrexed-bevacizumab-carboplatin, $n=133$ ) were evaluable. The median age was 71 years in pemetrexed-bevacizumab and 72 years in pemetrexed-bevacizumab-carboplatin. Median PFS time was 4.8 months in pemetrexed-bevacizumab and 6.8 months in pemetrexed-bevacizumab-carboplatin. In a treatment comparison using the Wilcoxon test for the subgroup analysis of patients with ECOG PS of 0-1 [pemetrexed-bevacizumab $(\mathrm{n}=112)$ and pemetrexed-bevacizumab-carboplatin $(\mathrm{n}=126)]$, the HR was 1.31 (95\% CI, 0.99-1.73; $\mathrm{P}=0.0426)$. The ORR was $31.4 \%$ in pemetrexed-bevacizumab vs. $44.4 \%$ in pemetrexed-bevacizumab-carboplatin $(\mathrm{P}=0.0343)$. Median OS time was 11.6 months in pemetrexed-bevacizumab vs. 15.2 months in pemetrexed-bevacizumab-carboplatin (HR=1.20, 95\% CI, 0.85-1.70; $\mathrm{P}=0.2050$ ). The 1-year survival rates were 48.2 and $58.8 \%$, respectively. In comparison, the median OS time in the small group of patients with ECOG PS2 was 11.5 months in pemetrexed-bevacizumab $(n=6)$ and 3.8 months in pemetrexed-bevacizumab-carboplatin $(n=7)(43)$.

A total of 76 patients (64.4\%) reported grade $3 / 4$ AEs in pemetrexed-bevacizumab and 87 patients $(65.4 \%)$ in pemetrexed-bevacizumab-carboplatin; 58 patients (49.2\%) in pemetrexed-bevacizumab and 64 patients $(48.1 \%)$ in pemetrexed-bevacizumab-carboplatin had serious AEs. A total of 46 patients (39.0\%) in pemetrexed-bevacizumab and
69 patients (51.9\%) in pemetrexed-bevacizumab-carboplatin received maintenance therapy. The combination of pemetrexed-bevacizumab-carboplatin demonstrated efficacy, particularly in PS0-1 patients, with an acceptable toxicity profile in elderly patients (43).

Ongoing pemetrexed clinical trials dedicated to PS2 patients First-line pemetrexed combination therapy. In 2013, Lilenbaum et al reported results from the randomized, phase 2, the Trial of Poor Performance Status Patients (ToPPs) trial at the 15th World Conference on Lung Cancer Meeting (Table IV) (42). Patients with previously untreated non-squamous stage IIIB or IV NSCLC and PS2 were randomized 1:1:1 to receive pemetrexed $\left(500 \mathrm{mg} / \mathrm{m}^{2} \mathrm{q} 3 \mathrm{w}\right)$ (Arm 1), pemetrexed (500 mg/m $\left.\mathrm{m}^{2} \mathrm{q} 3 \mathrm{w}\right)$ with bevacizumab (15 mg/kg q3w) (Arm 2) or pemetrexed $\left(500 \mathrm{mg} / \mathrm{m}^{2} \mathrm{q} 3 \mathrm{w}\right)$ with bevacizumab $(15 \mathrm{mg} / \mathrm{kg} \mathrm{q} 3 \mathrm{w})$ and carboplatin (AUC $=5 \mathrm{q} 3 \mathrm{w}$ ) (Arm 3) for a maximum of 4 cycles. Patients were evaluated every 2 cycles. The primary endpoint was PFS.

Among the 163 randomized patients (median age, $\sim 72$ years), the ORRs were $14.6 \%$ (95\% CI, 6.1-27.8) in Arm 1, 25.4\% (95\% CI, 15.0-38.4) in Arm 2 and 39.3\% (95\% CI, 26.5-53.3) in Arm 3 (42). The median time to progression was 3.5 (95\% CI, 1.6-6.4) months in Arm 1, 4.9 (95\% CI, 3.1-8.0) months in Arm 2, and 5.3 (95\% CI, 3.2-7.1) months in Arm 3. The median PFS was 2.6 (95\% CI, 1.5-5.1) months in Arm 1, 3.5 (95\% CI, 2.4-5.1) months in Arm 2 and 4.1 (95\% CI, 3.0-6.4) months in Arm 3 (Table IV). The median OS was 7.6 (95\% CI, 3.0-10.7) months in Arm 1, 8.7 (95\% CI, 5.0-11.3) months in Arm 2, and 8.8 (95\% CI, 5.4-13.4) months in Arm 3.

Grade 3 bevacizumab-associated AEs in Arm 2 were thromboembolic events (5.6\%), hypertension (3.7\%), and hemorrhage (1.9\%), and in Arm 3 were thromboembolic events $(7.7 \%)$, hypertension $(1.9 \%)$ and proteinuria (1.9\%) (42). Thromboembolic events were the only grade 4 bevacizumab-associated AEs (1.9\% Arm 2 and 3.8\% Arm 3). There were no treatment-related deaths in Arm 1. There were 3 treatment-related deaths (cerebrovascular accident, acute respiratory distress syndrome, and pulmonary embolism) in Arm 2 and 1 death (seizure) in Arm 3. Currently, this study is ongoing but not recruiting patients.

An open-label, single-arm study is ongoing, actively recruiting patients with non-squamous NSCLC who are at least 65 years old or have a PS of 2, and testing first-line pemetrexed and carboplatin combination followed by pemetrexed maintenance (Table III) (38).

\section{Discussion}

Because poor PS is an independent prognostic factor in NSCLC (12-16), PS scores are widely used by oncologists to guide treatment decisions. Historically, PS2 patients with advanced NSCLC had poor outcomes in randomized clinical trials (48-50), and early evidence suggested that therapy may have been detrimental in these patients $(49,50)$. Thus, there has been a tendency to limit enrollment to patients with a PS $\leq 1$. However, several recent trials have included PS2 NSCLC patients. The determination of PS scores as assessed by oncologists and other health care professionals can differ from patient-assessed PS (11). Nonetheless, health care profes- 
sional-rated PS scores are prognostic, reliable and similar in accuracy to patient-reported PS scores, comparing favorably with the patient-reported PS scores $(11,51,52)$.

Especially challenging are patients with a score between PS1 and PS2. The subjective determination of PS2 scores could affect the types of treatments offered (53). Also problematic are comorbid conditions (frequently measured by the Charlson Comorbidity Index) (54) that are independent of cancer; comorbidity may influence both PS and tolerance for cancer treatment. Despite the problems intrinsic to PS measurements, these measures are widely used and accepted given their reproducible capacity to assess prognosis and predict tolerability of treatment. However, with recent improvements in supportive care and improved tolerability and efficacy of anticancer agents in the treatment of advanced NSCLC, there has been a need to clarify the potential benefits of anticancer therapy in patients who have a PS of 2 .

Until recently, treatment recommendations for PS2 patients were in part driven by the results of the cooperative group trial (EST 1581) published in 1986 (48). Between 1981 and 1983, EST 1581 randomized 486 patients with metastatic NSCLC to one of the four active regimens at the time: cyclophosphamide, doxorubicin, methotrexate and procarbazine; mitomycin, vinblastine and cisplatin; etoposide and cisplatin; or vindesine and cisplatin. Most of the severe toxicity occurred in the $19 \%$ of patients who had a PS of 2 at baseline (48). On the basis of these results, the authors suggested that patients with a PS of 2 be excluded from future phase 3 trials (48).

A later phase 3 cooperative group trial (ECOG 1594) investigating newer platinum-containing regimens initially included patients with advanced NSCLC and a PS of 2, but the protocol was later amended to exclude patients with a PS of 2 because of a high rate of serious AEs in these patients (49). On the basis of the toxicity and poorer outcomes of patients with a PS of 2 relative to those with a PS of 0-1, the authors concluded that the routine use of platinum-based combination chemotherapy in patients with poor PS was not recommended (49). A subsequent retrospective analysis of ECOG 1594 suggested that the worse outcomes of PS2 patients were related to the disease, not the treatment (50).

The ECOG 1599 trial was the first US cooperative group trial that specifically enrolled patients with a PS of 2 and NSCLC (55). In an attempt to maximize tolerability, this phase 2 trial randomized PS2 patients to receive first-line treatment with dose-attenuated carboplatin plus paclitaxel (the least toxic combination from ECOG 1594) and doseattenuated gemcitabine plus cisplatin, which yielded a median OS of 7.9 months in patients with a PS of 2 in ECOG $1594(50,55)$. One hundred patients were eligible to receive treatment. The 1 -year OS rate was $25 \%$ for carboplatin plus paclitaxel and $19 \%$ for gemcitabine plus cisplatin. The authors concluded that platinum-based chemotherapy was feasible with acceptable toxicity in PS2 patients with NSCLC and that a randomized trial comparing a non-platinum single agent with a platinum doublet was needed in patients with a PS of 2 (55).

On the basis of historical studies and clinical experience, many clinical trials still exclude PS2 patients, leading to a paucity of data in this patient population (as evidenced by the few clinical trials reported in this review). Because of the lack of robust clinical trial data, there is still no consensus on the best chemotherapy for patients with poor PS. On the basis of emerging data, treatment guidelines are evolving. In ESMO guidelines published in 2010, single-agent chemotherapy was the preferred option in PS2 (and elderly) patients, although 'selected' PS2 patients (and elderly patients with good PS) could be offered combination chemotherapy (56). The most recent ASCO guidelines, published in 2011 (prior to the publication of some of the studies evaluating platinum doublets versus single-agent treatments in poor PS chemonaive patients), suggest that data are insufficient to make a recommendation for chemotherapy doublets in PS2 patients (Table I) (3). The ESMO guidelines, published in 2014, now suggest carboplatin-based doublet therapy should be considered in eligible PS2 patients (Table I) (4).

Although patients with a PS of 2 have worse outcomes when compared with those with a PS of 0-1, regardless of whether they receive pemetrexed $(28,36,37,40,41)$ or other agents $(48-50,57,58)$, recent data from completed trials show that among PS2 patients, chemonaive patients receiving combination treatment have improved outcomes with acceptable safety compared to those receiving single-agent treatment (19-24). Many of these studies include non-pemetrexed regimens. In the CALGB 9730 trial, in a preplanned subset analysis, chemonaive PS2 patients receiving carboplatin with paclitaxel experienced improved OS relative to PS2 patients receiving paclitaxel as a single agent (median OS was 4.7 vs. 2.4 months; $\mathrm{P}=0.016$ ) (21). In a phase 3 trial, Reynolds et al randomized chemonaive PS2 patients to gemcitabine as a single agent or gemcitabine plus carboplatin; patients receiving combination therapy experienced significantly improved ORR (21.1 vs. $6.3 \%$; $\mathrm{P}=0.01$ ). However, median OS and PFS were not statistically significant in the gemcitabine plus carboplatin group versus the single-agent gemcitabine group (median OS of 6.7 vs. 5.1 months; $\mathrm{P}=0.24$ ) (median $\mathrm{PFS}$ of 3.8 vs. 2.7 months; $\mathrm{P}=0.14)$ (22). Gemcitabine and carboplatin is not an approved combination therapy.

Likewise, data from the European Union have also shown that chemonaive PS2 patients experience improved outcomes when treated with combination therapy (23). In the phase 3 CAPPA-2 study, chemonaive PS2 patients were randomized to receive first-line treatments of gemcitabine plus cisplatin and gemcitabine (23). The study was stopped after enrollment of 57 patients as a result of slow accrual. Among these patients, those receiving combination therapy experienced improved median OS (5.9 vs. 3.0 months; $\mathrm{P}=0.039)$, median PFS (3.3 vs. 1.7 months; $\mathrm{P}=0.017$ ) and response ( 18 vs. $4 \% ; \mathrm{P}=0.19)$ without a substantial increase in toxicity.

Pemetrexed is better tolerated than gemcitabine, paclitaxel and docetaxel and has been shown to be at least equally effective in non-squamous NSCLC patients with PS $0-1(28,31,44,59)$. Thus, given the previously mentioned results supporting the use of platinum doublets in PS2 chemonaive NSCLC patients, it is tenable that a platinum doublet containing pemetrexed would also be promising as first-line therapy in PS2 patients with advanced NSCLC. This was demonstrated in the study by Zukin et al, in which PS2 patients receiving first-line pemetrexed plus carboplatin had improved OS (with acceptable safety) relative to patients receiving single-agent 
pemetrexed (19). Pemetrexed and carboplatin is not an approved combination therapy.

Completed results are pending in the ongoing study, ToPPs, in which chemonaive patients were randomized to receive pemetrexed plus bevacizumab and pemetrexed plus bevacizumab and carboplatin. Preliminary results show numerically improved outcomes compared to patients receiving pemetrexed monotherapy (42). Bevacizumab and pemetrexed is not an approved combination therapy.

To our knowledge, there are no published data assessing pemetrexed as second-line cytotoxic chemotherapy in PS2 patients aside from the study by Hanna et al (28), and there are few clinical data on NSCLC patients with PS2 who received maintenance cytotoxic chemotherapy. To date, there are no pemetrexed trials on maintenance therapy in PS2 patients. There have been a few studies on the role of maintenance therapy with gemcitabine in PS2 patients. In the Central ECOG trial of continuation maintenance with gemcitabine after cisplatin-gemcitabine induction therapy, Brodowicz et al reported that a survival benefit for maintenance therapy was observed only in patients with good PS (60). For patients with a KPS >80 ( $=99)$, median OS was 8.3 months with BSC and 22.9 months with gemcitabine (HR=2.1; 95\% CI, 1.2-3.8). For patients with a KPS $\leq 80(n=107)$, median OS was 7.7 with BSC and 7.0 months with gemcitabine $(\mathrm{HR}=0.8$; 95\% CI, 0.5-1.3). However, the authors caution that this was an unplanned subset analysis. Belani et al assessed gemcitabine continuation maintenance vs. BSC after carboplatin-gemcitabine induction chemotherapy (61). In this trial, $25 \%$ of patients had a PS $\geq 2$ at the time of randomization. Although this trial did not specifically report results for PS2 patients, survival was not improved with gemcitabine maintenance therapy for the overall population. However, maintenance gemcitabine was tolerable, albeit with higher rates of grade 3-4 toxicities. With more effective induction regimens that have better therapeutic indices, it might be possible in the future to explore the role of maintenance treatment in patients with advanced NSCLC and a PS of 2.

Recently, in a meta-analysis including 2,671 patients with non-squamous NSCLC and good PS who were treated with a pemetrexed-containing regimen as first- or second-line or maintenance therapy, the effect of pemetrexed on OS was similar in younger and older patients as evidenced by the pooled HR ratio close to 1 . The authors concluded that pemetrexed is an efficacious treatment for advanced non-squamous NSCLC, regardless of patient age (62). The final efficacy and safety results of pemetrexed continuation maintenance therapy in the elderly from the phase 3 PARAMOUNT study showed that continuation maintenance pemetrexed had comparable survival and toxicity profiles in the elderly and non-elderly subgroups (63). In the present review, we identified a German multicenter study in elderly patients, in which the combination of pemetrexedbevacizumab-carboplatin demonstrated efficacy, particularly in PS0-1 patients, with an acceptable toxicity profile (43).

It should be noted that this review has several limitations. These include a small number of clinical trials, some of which were subject to retrospective subset analyses. Although prospective clinical trials were included in this review, patient numbers are relatively small and patient enrollment may have been subject to investigator bias with respect to the assessment of PS2. It is also possible that the PS2 patient populations enrolled in these clinical trials may not be representative of patients in community practice in that patients with excessive or specific comorbidities may not have met the inclusion criteria for a clinical trial. Additionally, although pemetrexed (with vitamin supplementation) is now indicated for use in patients with non-squamous NSCLC $(26,32)$, some of the earlier clinical trials included in this review enrolled patients with squamous NSCLC and/or did not require vitamin supplementation, preventing meaningful subset analyses. Other limitations of this review are as follows: i) investigator bias in assessing progressive disease; ii) lack of placebo-controlled trials; and iii) only 1 trial that met its primary endpoint.

\section{Conclusion}

Patients with a PS of 2 represent a heterogeneous population. Doublet regimens can improve the response rate and survival in PS2 patients (19-24). Consequently, doublet combinations, such as pemetrexed plus carboplatin, are an option in PS2 patients with non-squamous NSCLC (19). Pemetrexed plus carboplatin is not an approved combination therapy. Single-agent therapy remains an option for PS2 chemonaive patients with excessive comorbidities and those who cannot tolerate combination therapy. Finally, supportive care with a focus on palliation of symptoms is important for all patients; quality of life should be a key determinant in selecting treatment.

\section{Acknowledgements}

The authors thank Dr Andrew Koustenis, of Eli Lilly and Company, for providing a critical review of the manuscript. Writing and editorial assistance for the development of this manuscript was provided by inVentiv Health Clinical with the financial support of Eli Lilly and Company. The authors would like to acknowledge Sharad Wankhade, $\mathrm{PhD}$, and Noelle Gasco, employees of inVentiv Health Clinical, for writing and editorial support. C.V.G. and C.O. are employees of Eli Lilly and Company. R.Z. received financial support for travel and research from Eli Lilly and Company. D.R.S. has no conflict of interest. Eli Lilly and Company provided financial support for the preparation of the article.

\section{References}

1. Ferlay J, Soerjomataram I, Ervik M, Dikshit R, Eser S, Mathers C, Rebelo M, Parkin DM, Forman D and Bray F: GLOBOCAN 2012 v1.0, Cancer Incidence and Mortality Worldwide: IARC CancerBase No. 11 (Internet). International Agency for Research on Cancer, Lyon, France, 2013. http://globocan.iarc. fr/Pages/fact_sheets_population.aspx. Accessed March 5, 2014.

2. Non-small Cell Lung Cancer Collaborative Group: Chemotherapy in non-small cell lung cancer: A meta-analysis using updated data on individual patients from 52 randomised clinical trials. BMJ 311: 899-909, 1995.

3. Azzoli CG, Temin S, Aliff T, Baker S, Brahmer J, Johnson DH, Laskin JL, Masters G, Milton D, Nordquist L, et al: 2011 focused update of 2009 American Society of Clinical Oncology Clinical Practice guideline update on chemotherapy for stage IV non-small-cell lung cancer. J Clin Oncol 29: 3825-3831, 2011

4. Reck M, Popat S, Reinmuth N, De Ruysscher D, Kerr KM and Peters S; ESMO Guidelines Working Group: Metastatic non-small-cell lung cancer (NSCLC): ESMO Clinical Practice Guidelines for diagnosis, treatment and follow-up. Ann Oncol 25 (suppl 3): iii27-iii39, 2014. 
5. NCCN: NCCNClinical Practice Guidelines in Oncology. Non-smal cell lung cancer, V.5. 2015. National Comprehensive Cancer Network, 2015. http://www.nccn.org/professionals/physician gls/pdf/nscl.pdf. Accessed March 19, 2015.

6. Oken MM, Creech RH, Tormey DC, Horton J, Davis TE, McFadden ET and Carbone PP: Toxicity and response criteria of the Eastern Cooperative Oncology Group. Am J Clin Oncol 5: 649-655, 1982.

7. Schag CC, Heinrich RL and Ganz PA: Karnofsky performance status revisited: Reliability, validity, and guidelines. J Clin Oncol 2: 187-193, 1984

8. Buccheri G, Ferrigno D and Tamburini M: Karnofsky and ECOG performance status scoring in lung cancer: A prospective longitudinal study of 536 patients from a single institution. Eur J Cancer 32A: 1135-1141, 1996.

9. Kelly K: Challenges in defining and identifying patients with non-small cell lung cancer and poor performance status. Semin Oncol 31 (suppl 11): 3-7, 2004.

10. Radzikowska E, Glaz P and Roszkowski K: Lung cancer in women: Age, smoking, histology, performance status, stage, initial treatment and survival. Population based study of 20561 cases. Ann Oncol 13: 1087-1093, 2002.

11. Lilenbaum RC, Cashy J, Hensing TA, Young S and Cella D: Prevalence of poor performance status in lung cancer patients: Implications for research. J Thorac Oncol 3: 125-129, 2008

12. Albain KS, Crowley JJ, LeBlanc M and Livingston RB: Survival determinants in extensive-stage non-small-cell lung cancer: The Southwest Oncology Group experience. J Clin Oncol 9: 1618-1626, 1991.

13. Ando M, Ando Y, Sugiura S, Minami H, Saka H, Sakai S, Shimokata K and Hasegawa Y: Prognostic factors for short-term survival in patients with stage IV non-small cell lung cancer. Jpn J Cancer Res 90: 249-253, 1999.

14. Brundage MD, Davies D and Mackillop WJ: Prognostic factors in non-small cell lung cancer: A decade of progress. Chest 122 1037-1057, 2002

15. Stanley KE: Prognostic factors for survival in patients with inoperable lung cancer. J Natl Cancer Inst 65: 25-32, 1980.

16. Takigawa N, Segawa Y, Okahara M, Maeda Y, Takata I, Kataoka $M$ and Fujii M: Prognostic factors for patients with advanced non-small cell lung cancer: Univariate and multivariate analyses including recursive partitioning and amalgamation. Lung Cancer 15: 67-77, 1996.

17. Langer $C$ and Lilenbaum R: Role of chemotherapy in patients with poor performance status and advanced non-small cell lung cancer. Semin Oncol 31 (suppl 11): 8-15, 2004.

18. Lee L, Cheung WY, Atkinson E and Krzyzanowska MK: Impact of comorbidity on chemotherapy use and outcomes in solid tumors: A systematic review. J Clin Oncol 29: 106-117, 2011.

19. Zukin M, Barrios CH, Pereira JR, Ribeiro Rde A, Beato CA, do Nascimento YN, Murad A, Franke FA, Precivale M, Araujo LH, et al: Randomized phase III trial of single-agent pemetrexed versus carboplatin and pemetrexed in patients with advanced non-small-cell lung cancer and Eastern Cooperative Oncology Group Performance Status of 2. J Clin Oncol 31: 2849-2853, 2013

20. Lilenbaum R, Axelrod R, Thomas S, Dowlati A, Seigel L, Albert D, Witt K and Botkin D: Randomized phase II trial of erlotinib or standard chemotherapy in patients with advanced non-small-cell lung cancer and a performance status of 2 . J Clin Oncol 26: 863-869, 2008.

21. Lilenbaum RC, Herndon JE, List MA, Desch C, Watson DM, Miller AA, Graziano SL, Perry MC, Saville W, Chahinian P, et al: Single-agent versus combination chemotherapy in advanced non-small-cell lung cancer: The Cancer and Leukemia Group B (study 9730). J Clin Oncol 23: 190-196, 2005.

22. Reynolds C, Obasaju C, Schell MJ, Li X, Zheng Z, Boulware D, Caton JR, DeMarco LC, O'Rourke MA, Shaw Wright G, et al Randomized phase III trial of gemcitabine-based chemotherapy with in situ RRM1 and ERCC1 protein levels for response prediction in non-small-cell lung cancer. J Clin Oncol 27: 5808-5815, 2009.

23. Morabito A, Gebbia V, Di Maio M, Cinieri S, Viganò MG, Bianco R, Barbera S, Cavanna L, De Marinis F, Montesarchio V, et al: Randomized phase III trial of gemcitabine and cisplatin vs. gemcitabine alone in patients with advanced non-small cell lung cancer and a performance status of 2: The CAPPA-2 study. Lung Cancer 81: 77-83, 2013.
24. Lilenbaum R, Villaflor VM, Langer C, O'Byrne K, O'Brien M, Ross HJ, Socinski M, Oldham FB, Sandilac L, Singer JW, et al: Single-agent versus combination chemotherapy in patients with advanced non-small cell lung cancer and a performance status of 2: Prognostic factors and treatment selection based on two large randomized clinical trials. J Thorac Oncol 4: 869-874, 2009.

25. Shih C, Habeck LL, Mendelsohn LG, Chen VJ and Schultz RM: Multiple folate enzyme inhibition: Mechanism of a novel pyrrolopyrimidine-based antifolate LY231514 (MTA). Adv Enzyme Regul 38: 135-152, 1998.

26. Alimta [package insert]. Indianapolis, IN: Eli Lilly and Company; 2013.

27. Ciuleanu T, Brodowicz T, Zielinski C, Kim JH, Krzakowski M, LaackE, Wu Y-L, Bover I, Begbie S, Tzekova V, et al: Maintenance pemetrexed plus best supportive care versus placebo plus best supportive care for non-small-cell lung cancer: A randomised, double-blind, phase 3 study. Lancet 374: 1432-1440, 2009.

28. Hanna N, Shepherd FA, Fossella FV, Pereira JR, De Marinis F, von Pawel J, Gatzemeier U, Tsao TCY, Pless M, Muller T, et al: Randomized phase III trial of pemetrexed versus docetaxel in patients with non-small-cell lung cancer previously treated with chemotherapy. J Clin Oncol 22: 1589-1597, 2004.

29. Paz-Ares L, de Marinis F, Dediu M, Thomas M, Pujol JL, Bidoli P, Molinier O, Sahoo TP, Laack E, Reck M, et al: Maintenance therapy with pemetrexed plus best supportive care versus placebo plus best supportive care after induction therapy with pemetrexed plus cisplatin for advanced non-squamous non-small-cell lung cancer (PARAMOUNT): A double-blind, phase 3, randomised controlled trial. Lancet Oncol 13: 247-255, 2012.

30. Paz-Ares LG, de Marinis F, Dediu M, Thomas M, Pujol JL, Bidoli P, Molinier O, Sahoo TP, Laack E, Reck M, et al: PARAMOUNT: Final overall survival results of the phase III study of maintenance pemetrexed versus placebo immediately after induction treatment with pemetrexed plus cisplatin for advanced nonsquamous non-small-cell lung cancer. J Clin Oncol 31: 2895-2902, 2013.

31. Scagliotti GV, Parikh P, von Pawel J, Biesma B, Vansteenkiste J, Manegold C, Serwatowski P, Gatzemeier U, Digumarti R, Zukin M, et al: Phase III study comparing cisplatin plus gemcitabine with cisplatin plus pemetrexed in chemotherapy-naive patients with advanced-stage non-small-cell lung cancer. J Clin Oncol 26: 3543-3551, 2008.

32. European Medicines Agency (EMEA). Committee for Medicinal Products for Human Use (CHMP): Alimta. EMEA/H/C/000564 2011. http://www.ema.europa.eu/ema/index.jsp?curl=pages/ medicines/human/medicines/000564/human_med_000638.jsp \&mid=WC0b01ac058001d124. Accessed March 19, 2015.

33. Vogelzang NJ, Rusthoven JJ, Symanowski J, Denham C, Kaukel E, Ruffie P, Gatzemeier U, Boyer M, Emri S, Manegold C, et al: Phase III study of pemetrexed in combination with cisplatin versus cisplatin alone in patients with malignant pleural mesothelioma. J Clin Oncol 21: 2636-2644, 2003.

34. Clinicaltrials.gov: [Web site]. Available at: www.clinicaltrials. gov. Accessed: March 19, 2015

35. Clinicaltrialsregister.eu: [Web site]. Available at: https://www. clinicaltrialsregister.eu/. Accessed: March 19, 2015.

36. Clarke SJ, Abratt R, Goedhals L, Boyer MJ, Millward MJ and Ackland SP: Phase II trial of pemetrexed disodium (ALIMTA, LY231514) in chemotherapy-naive patients with advanced non-small-cell lung cancer. Ann Oncol 13: 737-741, 2002

37. Gridelli C, Kaukel E, Gregorc V, Migliorino MR, Müller TR, Manegold C, Favaretto A, Martoni A, Caffo O, Schmittel A, et al: Single-agent pemetrexed or sequential pemetrexed/gemcitabine as front-line treatment of advanced non-small cell lung cancer in elderly patients or patients ineligible for platinum-based chemotherapy: A multicenter, randomized, phase II trial. J Thorac Oncol 2: 221-229, 2007

38. Fudan University. A study of PC sequential pemetrexed single drug maintenance treatment for NSCLC and related predictive biomarkers. ClinicalTrials.gov [Internet]. http://www.clinicaltrials.gov/ct2/results?term=NCT01860508 NLM Identifier NCT01860508. Accessed March 19, 2015.

39. M.D. Anderson Cancer Center and Eli Lilly and Company. Single agent Alimta in poor performance status in non-small cell lung cancer. ClinicalTrials.gov [Internet]. http://www.clinicaltrials.gov/ct2/results?term=NCT00508144 NLM Identifier NCT00508144. Accessed March 19, 2015. 
40. Blakely LJ, Schwartzberg L, Keaton M, Schnell F, Henry D Epperson A and Walker MS: A phase II trial of pemetrexed and gemcitabine as first line therapy for poor performance status and/or elderly patients with stage IIIB/IV non-small cell lung cancer. Lung Cancer 66: 97-102, 2009.

41. Grønberg BH, Bremnes RM, Fløtten O, Amundsen T, Brunsvig PF, Hjelde HH, Kaasa S, von Plessen C, Stornes F, Tollali T, et al: Phase III study by the Norwegian lung cancer study group: Pemetrexed plus carboplatin compared with gemcitabine plus carboplatin as first-line chemotherapy in advanced non small cell lung cancer. J Clin Oncol 27: 3217-3224, 2009.

42. Lilenbaum R, Hainsworth J, Joseph M, Shipley D, Hagan K, Thompson D, Greco F, Burris H and Spigel D: Randomized phase II study of pemetrexed v. pemetrexed/bevacizumab v. carboplatin/pemetrexed/bevacizumab in patients with previously untreated advanced non-squamous non-small-cell lung cancer and poor performance status. J Thorac Oncol 8 (Suppl 2): S889-S890, 2013.

43. Schuette W, Nagel S, Schneider CP, Engel-Riedel W, Schumann C, Kohlhaeufl M, Serke M, Hoeffken G, Kortsik C, Reck M, et al: 65 plus: A randomized phase III trial of pemetrexed and bevacizumab versus pemetrexed, bevacizumab, and carboplatin as first-line treatment for elderly patients with advanced nonsquamous, non-small cell lung cancer (NSCLC). ASCO Annual Meeting. J Clin Oncol 31: abs 8013, 2013.

44. Shepherd FA, Dancey J, Ramlau R, Mattson K, Gralla R, O'Rourke M, Levitan N, Gressot L, Vincent M, Burkes R, et al: Prospective randomized trial of docetaxel versus best supportive care in patients with non-small-cell lung cancer previously treated with platinum-based chemotherapy. J Clin Oncol 18 2095-2103, 2000.

45. Fossella FV, DeVore R, Kerr RN, Crawford J, Natale RR, Dunphy F, Kalman L, Miller V, Lee JS, Moore M, et al: Randomized phase III trial of docetaxel versus vinorelbine or ifosfamide in patients with advanced non-small-cell lung cancer previously treated with platinum-containing chemotherapy regimens. The TAX 320 Non-Small Cell Lung Cancer Study Group. J Clin Oncol 18: 2354-2362, 2000.

46. Scagliotti G, Hanna N, Fossella F, Sugarman K, Blatter J, Peterson P, Simms L and Shepherd FA: The differential efficacy of pemetrexed according to NSCLC histology: A review of two Phase III studies. Oncologist 14: 253-263, 2009.

47. Scagliotti G, Brodowicz T, Shepherd FA, Zielinski C, Vansteenkiste J, Manegold C, Simms L, Fossella F, Sugarman K and Belani CP: Treatment-by-histology interaction analyses in three phase III trials show superiority of pemetrexed in nonsquamous non-small cell lung cancer. J Thorac Oncol 6: 64-70, 2011.

48. Ruckdeschel JC, Finkelstein DM, Ettinger DS, Creech RH, Mason BA, Joss RA and Vogl S: A randomized trial of the four most active regimens for metastatic non-small-cell lung cancer. J Clin Oncol 4: 14-22, 1986.

49. Schiller JH, Harrington D, Belani CP, Langer C, Sandler A, Krook J, Zhu J and Johnson DH; Eastern Cooperative Oncology Group: Comparison of four chemotherapy regimens for advanced non-small-cell lung cancer. N Engl J Med 346: 92-98, 2002.

50. Sweeney CJ, Zhu J, Sandler AB, Schiller J, Belani CP, Langer C, Krook J, Harrington D and Johnson DH: Outcome of patients with a performance status of 2 in Eastern Cooperative Oncology Group Study E1594: A Phase II trial in patients with metastatic non-small cell lung carcinoma. Cancer 92: 2639-2647, 2001.

51. Ando M, Ando Y, Hasegawa Y, Shimokata K, Minami H, Wakai K, Ohno Y and Sakai S: Prognostic value of performance status assessed by patients themselves, nurses, and oncologists in advanced non-small cell lung cancer. Br J Cancer 85: 1634-1639, 2001.
52. Blagden SP, Charman SC, Sharples LD, Magee LR and Gilligan D: Performance status score: Do patients and their oncologists agree? Br J Cancer 89: 1022-1027, 2003.

53. Morère JF, Bréchot JM, Westeel V, Gounant V, Lebeau B, Vaylet F, Barlési F, Urban T, Souquet P-J, Debieuvre D, et al: Randomized phase II trial of gefitinib or gemcitabine or docetaxel chemotherapy in patients with advanced non-small-cell lung cancer and a performance status of 2 or 3 (IFCT-0301 study). Lung Cancer 70: 301-307, 2010.

54. Charlson ME, Pompei P, Ales KL and MacKenzie CR: A new method of classifying prognostic comorbidity in longitudinal studies: Development and validation. J Chronic Dis 40: 373-383, 1987.

55. Langer C, Li S, Schiller J, Tester W, Rapoport BL and Johnson DH; Eastern Cooperative Oncology Group: Randomized phase II trial of paclitaxel plus carboplatin or gemcitabine plus cisplatin in Eastern Cooperative Oncology Group performance status 2 non-small-cell lung cancer patients: ECOG 1599. J Clin Oncol 25: 418-423, 2007.

56. D'Addario G, Früh M, Reck M, Baumann P, Klepetko W and Felip E; ESMO Guidelines Working Group: Metastatic non small-cell lung cancer: ESMO Clinical Practice Guidelines for diagnosis, treatment and follow-up. Ann Oncol 21 (suppl 5): v116-v119, 2010.

57. Perrone F, Di Maio M, Gallo C and Gridelli C: Outcome of patients with a performance status of 2 in the Multicenter Italian Lung Cancer in the Elderly Study (MILES). J Clin Oncol 22: 5018-5020, 2004.

58. Soria JC, Brisgand D and Le Chevalier T: Do all patients with advanced non small cell lung cancer benefit from cisplatin-based combination therapy? Ann Oncol 12: 1667-1670, 2001

59. Patel JD, Socinski MA, Garon EB, Reynolds CH, Spigel DR, Olsen MR, Hermann RC, Jotte RM, Beck T, Richards DA, et al: PointBreak: A randomized phase III study of pemetrexed plus carboplatin and bevacizumab followed by maintenance pemetrexed and bevacizumab versus paclitaxel plus carboplatin and bevacizumab followed by maintenance bevacizumab in patients with stage IIIB or IV nonsquamous non-small-cell lung cancer. J Clin Oncol 31: 4349-4357, 2013.

60. Brodowicz T, Krzakowski M, Zwitter M, Tzekova V, Ramlau R, Ghilezan N, Ciuleanu T, Cucevic B, Gyurkovits K, Ulsperger E, et al; for the Central European Cooperative Oncology Group: Cisplatin and gemcitabine first-line chemotherapy followed by maintenance gemcitabine or best supportive care in advanced non-small cell lung cancer: A phase III trial. Lung Cancer 52: 155-163, 2006

61. Belani CP, Waterhouse DM, Ghazal H, Ramalingam SS, Bordoni R, Greenberg R, Levine RM, Waples JM, Jiang Y and Reznikoff G: Phase III study of maintenance gemcitabine (G) and best supportive care (BSC) versus BSC, following standard combination therapy with gemcitabine carboplatin $(\mathrm{G}-\mathrm{Cb})$ for patients with advanced non-small cell lung cancer (NSCLC). ASCO Annual Meeting. J Clin Oncol 28: abs 7506, 2010.

62. Paz-Ares L, Zimmermann A, Ciuleanu T-E, Bunn PA, San Antonio B, Denne J, Iturria N, John WJ and Scagliotti GV: Meta-analysis examining impact of age on pemetrexed (pem) efficacy for the treatment of advanced nonsquamous (NS) non-small cell lung cancer (NSCLC). J Clin Oncol 32: abs e19040, 2014.

63. Gridelli C, de Marinis F, Thomas M, Prabhash K, El Kouri C, Blackhall F, Bustin F, Pujol JL, John WJ, San Antonio B, et al: Final efficacy and safety results of pemetrexed continuation maintenance therapy in the elderly from the PARAMOUNT phase III study. J Thorac Oncol 9: 991-997, 2014. 